\title{
Isolated pump erosion of an inflatable penile prosthesis through the scrotum in a diabetic patient
}

\author{
Raidh A. Talib, Ahmad Shamsodini, Emad A. Salem, Onder Canguven, \\ Abdulla Al Ansari \\ Urology Department - Hamad General Hospital, Doha, Qatar.
}

\begin{abstract}
ГSummary
Isolated pump erosion is a rare complication in patients with inflatable penile prosthesis. We describe a case of a diabetic patient who underwent inflatable penile prosthesis implantation with subsequent isolated pump erosion. Repeated attempts of conservative repair of the erosion failed. Finally, the inflatable penile prosthesis was replaced with a malleable one to avoid new pump erosion. In case of isolated pump erosion, replacement of the inflatable penile prosthesis with a malleable one looks to be a good alternative salvage treatment for the patient.
\end{abstract}

KEY WORDS: Penile Prosthesis; Pump erosion; Diabetes.

\begin{abstract}
INTRODUCTION
Erectile dysfunction (ED) is defined as the inability to achieve or maintain an erection sufficient for satisfactory sexual performance. Surgical treatments are still reserved for men who cannot use or fail to respond to first and second line treatments. The insertion of a penile prosthesis (PP) provides an acceptable, definitive solution for ED. Although rare, PP is still subject to complications in the form of infection, erosion or mechanical failure. Isolated pump erosion without proven infection is an extra challenging problem for the surgeon. Herein, we describe our experience with malleable PP substitution to address isolated pump erosion.
\end{abstract}

\section{Case report}

A 60-year-old patient with ED secondary to adult onset of diabetes mellitus underwent implantation of an inflatable PP (American Medical Systems 700 Controlled Expansion) via a scrotal approach nearly one year ago. He was on insulin daily treatment and his preoperative glycosylated hemoglobin was $8.4 \%$. Preoperative prophylaxis was achieved by vancomycin $(500 \mathrm{mg}$ ) and gentamicin $(80 \mathrm{mg}$ ) injections. Strict sterile protocol, reduced operative time and minimization of hospital stay were achieved. Early postoperative days passed uneventful. Wound healing was a bit delayed without any sign of infection. On postoperative day 15 , after implantation, the patient started to complain from scrotal skin abrasion around the tip of PP pump with erythema, just far from the incision site. On examination, the pump was adherent to the skin with slight red discoloration over the pump site which then became dark in color (Figure 1). By that time, no signs of infection appeared at any other site of the PP components, no penile pain over the cylinders, and no mechanical problems with inflation or deflation of the PP were noticed. The leukocyte count was also normal. Dark red area over to pump site started to form incrustation, which has fallen later on leaving an ulcer (Figure 2).

Swabs were taken in two different times from around the pump and sent for culture that later revealed negative results. On postoperative day 30, after implantation, patient was admitted to hospital for relocation of pump, because the described ulcer widened and impending perforation was noticed. Under general anesthesia, complete excision of the ulcerated area was performed. The pump was placed to a new created space behind the testes. The wound was closed in layers and the pump was kept away 
Figure 1.

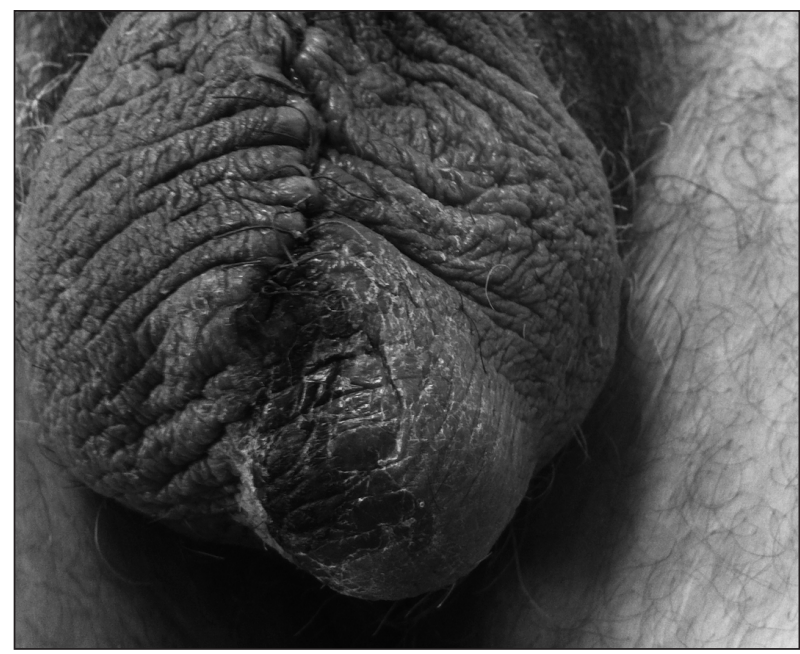

Figure 2.

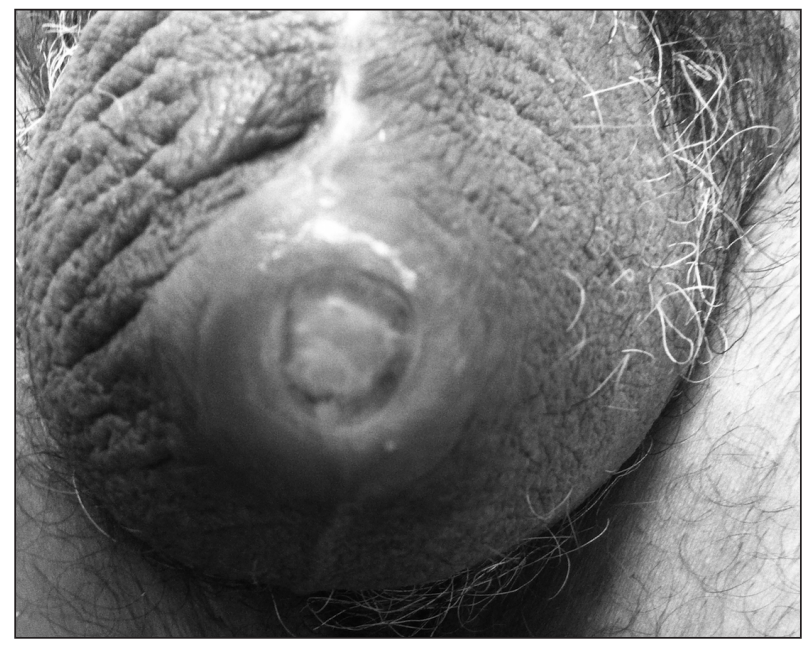

Figure 3.

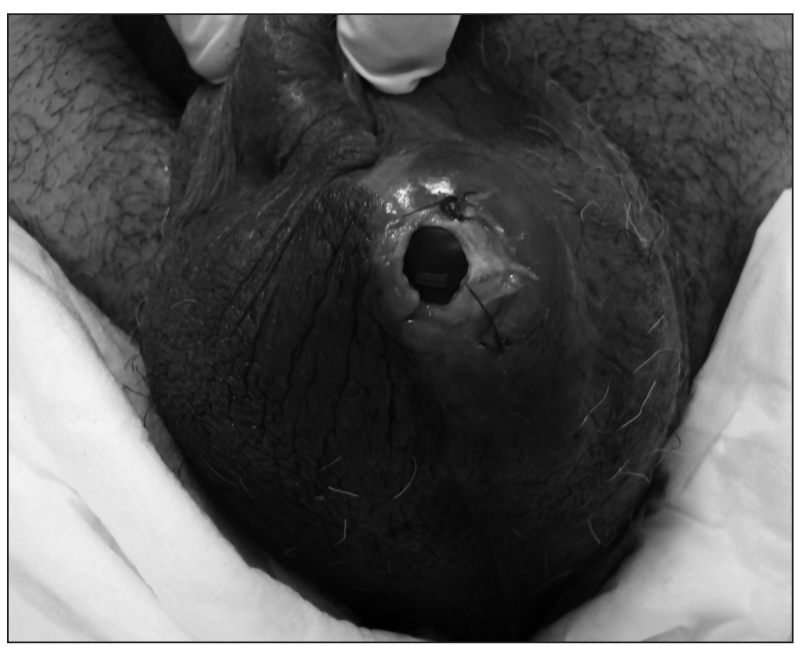

and separated by several layers from the skin. On postoperative day 20, after the relocation of pump, the erosion reurred. Under local anesthesia, the new small ulcer was managed and closed in layers. On postoperative day 30 , after the relocation of pump, the same sequence occurred for the third time ending in pump protrusion through the scrotal skin (Figure 3).

The patient was admitted for a salvage therapy eighty days after the PP implantation. Finally, the inflatable PP was replaced by a malleable one (Coloplast Genesis) to avoid further complications. Patient was empirically covered with vancomycin and gentamicin at time of admission and at time of surgery and underwent a thorough washout procedure as described by Mulcahy (1). The scrotal erosion site was loosely approximated with chromic sutures and was left to heal. Penrose drain was left just overnight. Patient was sent home on outpatient antibiotics (ciprofloxacin $500 \mathrm{mg}$ orally twice/day for two weeks and ceftriaxone $1 \mathrm{~g}$ intramuscular twice/day for seven days). A 9-month follow-up revealed no further problems.

\section{Discussion}

Our patient who had inflatable PP implantation developed isolated pump erosion on the scrotal skin. All endeavors to repair the pump erosion have failed with occurrence of the same problem. Total replacement of the inflatable PP with a malleable one showed to be a good choice to overcome isolated pump erosion. Nearly 40 years ago, Small et al. described paired sponge filled semirigid silicone PP for ED which could not be treated by means of medical therapies (2).

Today's PP can broadly be divided into inflatable and non-inflatable devices. Predictably, PPs are employed less often than medical therapies, but when utilized, satisfaction is almost always excellent. Unfortunately, the most worrisome postoperative complication is infection and erosion of PP $(1,3)$.

Isolated pump erosion through scrotal skin, to the best of our knowledge, has been discussed in few articles (4-6). Sawczuk and Wechsler were the first who reported isolated erosion of the pump of an inflatable PP through the scrotum in a diabetic patient (6). The same group was also the pioneers of insertion of malleable PP at the same sitting (6). Lately, Kohler et al. reported results of six patients with isolated scrotal pump erosion or infection in patients with inflatable PP (4). The latter group also suggested the malleable PP substitution technique provides an excellent option for management of isolated scrotal pump erosion or infection.

There are several described options for pump erosion, which include isolated removal and re-implantation of the scrotal pump, removal of the entire device with delayed re-implantation or immediate re-implantation. Although isolated removal and re-implantation of the scrotal pump is rarely described, in the largest published series, four out of four cases failed (7). Previous literatures clearly show that when tissue necrosis is occurring, the best option is to remove the prosthesis to relieve any pressure in the wound especially in diabetic patients. The pressure might be contributing to diminished blood sup- 
ply to the necrotic area. Since the immediate implantation of malleable PP eliminates the risk of consequent scarred corpora cavernosa secondary to removal of inflatable PP, it was successfully performed in other studies (4). However, it should also be noted that the malleable PP substitution is not a recommended technique if there is evidence of infection or erosion of the penile components of the prosthesis (4).

Although studies conducted for PP surgeries showed lower device complication rates, complications of PP included infection, hematomas, erosions, and malpositioning of the components.

Fortunately, isolated pump erosion was described in a small number of cases. However, diabetic patients, in particular, should be warned of the possibility of developing pump erosion through the scrotal skin. In case of isolated scrotal pump erosion, the malleable PP implantation provides a good option for management of this bothersome issue.

\section{REFERENCES}

1. Mulcahy JJ. Treatment alternatives for the infected penile implant. Int J Impot Res. 2003; 15(Suppl 5):S147-9.

2. Small MP. Small-Carrion penile prosthesis: a report on 160 cases and review of the literature. J Urol. 1978; 119:365-8.

3. Wilson SK, Zumbe J, Henry GD, et al. Infection reduction using antibiotic-coated inflatable penile prosthesis. Urology. 2007; $70: 337-40$

4. Kohler TS, Modder JK, Dupree JM, et al. Malleable implant substitution for the management of penile prosthesis pump erosion: a pilot study. J Sex Med. 2009; 6:1474-8.

5. Fitch WP, $3^{\text {rd }}$, Roddy T. Erosion of inflatable penile prosthesis reservoir into bladder. J Urol. 1986; 136:1080.

6. Sawczuk I, Wechsler M. Erosion of the pump mechanism of an inflatable penile prosthesis through the scrotum in a diabetic patient. J Natl Med Assoc. 1985; 77:577-8.

7. Wilson SK, Delk JR, $2^{\text {nd }}$. Inflatable penile implant infection: predisposing factors and treatment suggestions. J Urol. 1995; 153:659-61.

\section{Correspondence}

Raidh A. Talib, MD

Ahmad Shamsodini, MD

Emad A. Salem, MD

Abdulla Al Ansari, MD

Urology Department - Hamad General Hospital, 3050 Doha, Qatar

Onder Canguven, MD (Corresponding Author)

Associate Professor

Urology Department - Hamad General Hospital, 3050 Doha, Qatar

ocanguven@yahoo.com 